See discussions, stats, and author profiles for this publication at: https://www.researchgate.net/publication/233820012

\title{
Synergy of Cassini SAR and altimeter acquisitions for the retrieval of dune field characteristics on Titan
}

Conference Paper in Proceedings of SPIE - The International Society for Optical Engineering · September 2012 DOI: $10.1117 / 12.978185$

CITATIONS

3

8 authors, including:

Valerio Poggiali

Cornell University

36 PUBLICATIONS 308 CITATIONS

SEE PROFILE

Roberto Seu

Sapienza University of Rome

277 PUBLICATIONS 5,375 CITATIONS

SEE PROFILE

Some of the authors of this publication are also working on these related projects:

Monalisa View project

Corvara PSI Feasibility View project

\section{READS}

98

Marco Mastrogiuseppe

Sapienza University of Rome

62 PUBLICATIONS 480 CITATIONS

SEE PROFILE

Luca Pasolli

40 PUBLICATIONS 753 CITATIONS

SEE PROFILE 


\title{
Synergy of Cassini SAR and altimeter acquisitions for the retrieval of dune field characteristics on Titan
}

\author{
Valerio Poggiali $*^{\mathrm{a}}$, Marco Mastrogiuseppe ${ }^{\mathrm{a}}$, Mattia Callegari ${ }^{\mathrm{c}}$, Riccardo Martufi ${ }^{\mathrm{a}}$, \\ Roberto Seu ${ }^{a}$, Domenico Casarano ${ }^{b}$, Luca Pasolli $^{c}$, Claudia Notarnicola ${ }^{c}$ \\ ${ }^{\mathrm{a} D I E T}$, Sapienza Università di Roma, Italy; ${ }^{\mathrm{b}} \mathrm{CNR}$-IRPI, Via Amendola 122 I, Bari, Italy; \\ ${ }^{c}$ EURAC-Institute for Applied Remote Sensing, Viale Druso 1, Bolzano, Italy; \\ *valeriopoggiali@libero.it
}

\begin{abstract}
This work focuses on the retrieval of Titan's dune field characteristics addressing different radar modes. The main purpose of the proposed work is to exploit a possible synergy between SAR and altimeter acquisitions modes to provide information about dune field. Cassini has performed 86 Titan flybys in which several observations of dune fields have been collected in altimetry mode. There are several cases in which SAR and altimeter have been acquired over same areas covered by dune fields, such as during T28 (SAR) and T30 (altimeter) flybys. Altimetry together with SAR data have been used to derive the rms slopes of dunes (large scale) over Fensal area, this information has been employed to calculate SAR incidence angle with respect to dunes. We extracted backscattering coefficients of bright and dark areas detected in the analyzed SAR image in order to evaluate the angular response of scattering. Through the Geometric Optics model we retrieve roughness values (small scale rms slope) for both dune bright and dark areas.
\end{abstract}

Keywords: Synthetic aperture radar (SAR), Radar altimetry, Cassini, Dune field, Titan, electromagnetic models.

\section{INTRODUCTION}

The Cassini-Huygens mission has been collecting data about the Saturn system since 2004. Its RADAR instrument is a $\mathrm{Ku}$-band (2.17 $\mathrm{cm}$ wavelength) linearly polarized radar that alternatively operates in several modes: it can generate topographic profiles working as an altimeter, measure the emissivity as a radiometer, map the surface as a highresolution synthetic aperture radar (SAR) and measure the real aperture backscatter reflectivity as a scatterometer [1]. Cassini RADAR provided a vast amount of data, suggesting new scenarios for Titan's evolution. Several features, reflecting a complex morphology typical of an active land-atmosphere interaction, have been detected: impact craters, fluvial channels, "sand dunes" and lakes.

In the SAR operational mode Cassini obtains the highest resolution images revealing many topographic and geological features on Titan's surface. In particular vast longitudinal dune fields confined around the equatorial region, between $-30^{\circ}$ and $30^{\circ}$ latitude, have been discovered and it has been estimated that they cover $\sim 12.5 \%$ of the total Titan's surface [2].

Understanding the formation process of dunes, their morphology and distribution can reveal important clues on Titan's climatic and geological history. For instance, dunes shape could indicate the mean direction of wind flow and sand transport; their dimension could tell the quantity of sand supply; topographic and local climate conditions favorable to sand deposits can be predicted from a dune distribution analysis [3].

In section 2, the dataset used for this study is briefly outlined. In section 3 we retrieved information about dunes height from altimetry data. In the final section, by analyzing the dataset acquired by the Cassini RADAR instrument in SAR and altimetry mode we have estimated dunes rms slopes. Moreover, applying a suitable electromagnetic model to the SAR data, we inferred the roughness characteristic superimposed on a periodic surface which represents dune surface. 
Table 1. Dataset main characteristics

\begin{tabular}{|c|c|c|c|c|c|c|c|c|c|}
\hline SAR & Swath & Segment & Date & Longitude Range (deg E) & Latitude Range (deg) & Off-Nadir Angle* (deg) & Azimuth Angle* (deg) & Range Resolution* (km) & Azimuth Resolution* (km) \\
\hline & $\mathrm{T} 3$ & 1 & $02 / 15 / 2005$ & from -133.84 to -0.8125 & from -2.7813 to 22.5 & 20.2 & 275.8 & 0.485 & 0.494 \\
\hline & T17 & 1 & 09/07/2006 & from -69.25 to -32.406 & from 2.4688 to 15.688 & 35.5 & $-91,3$ & 0.278 & 0.274 \\
\hline & $\mathrm{T} 25$ & 1 & $02 / 22 / 2007$ & from -57.813 to 148.5 & from -35.375 to 85.688 & 23.7 & 155.5 & 0.495 & 0.393 \\
\hline & T28 & 1 & $04 / 10 / 2007$ & from -42.969 to 156.47 & from -20.625 to 80.938 & 20.9 & 155.4 & 0.623 & 0.447 \\
\hline & $\mathrm{T} 29$ & 1 & $04 / 26 / 2007$ & from -39.469 to 163.84 & from -4.2813 to 86.469 & 23.4 & 153.2 & 0.479 & 0.436 \\
\hline Altimeter & Track & Segment & Date & Longitude Range (deg E) & Latitude Range (deg) & Off-Nadir Angle*(deg) & SC_Altitude (km) & $\begin{array}{l}\text { 3-dB Footprint } \\
\text { Diameter (km) }\end{array}$ & MLE Heights (m) \\
\hline & $\mathrm{T} 30$ & inbound & $05 / 12 / 2007$ & from -28.265 to 6.267 & from -11.011 to 70.929 & $5.24 \times 10^{\wedge}-4$ & from 16186 to 959 & from 50.41 to 5.89 & from -847 to 289 \\
\hline
\end{tabular}

\section{DATASET DESCRIPTION}

We considered the following datasets: T3, T17, T25, T28 and T29 acquired using SAR operative mode and T30 acquired during altimetry mode over Fensal, a region located just north of the equator and almost centered at about $50^{\circ} \mathrm{W}$ longitude. SAR images show that the dunes present in this area tend to be more widely spaced with a brighter interdune with respect to other Titan's dune fields [2].

The dune field under investigation is located over an area that roughly extends from $15.0^{\circ} \mathrm{S}$ and $23.7^{\circ} \mathrm{N}$ and from $22.1^{\circ} \mathrm{W}-40.2^{\circ} \mathrm{W}$. The dataset includes all the SAR swaths and the altimetry tracks across this region of Titan (Fig. $2 \mathrm{a}$ ). Its main characteristics are reported on Table 1. The T3 and T17 SAR swaths cross this low northern latitudes region in an approximately E-W direction. In these swaths many dunes superimposed are observed on both intermediate and low backscatter plains, along with the craters Ksa, Menrva and Sinlap [22; 23].

T25, T28 and T29 swaths show wide overlaps over Fensal dune field in an approximately S-N direction, as well as the long T30 altimetry track. Part of the SAR images cover large intermediate to dark plains including dune fields, streaks, small hills, and circular to oval bright rim features of unknown origin [24].

From the overlapping of the T30 altimetry track on the T28 SAR image acquired over Fensal dune field, we selected the fully covered by dunes $-3 \mathrm{~dB}$ altimetry footprints.

\section{DUNES HEIGHT ESTIMATION FROM ALTIMETRY DATA}

The Cassini RADAR altimeter has operated for more than seven years generating topographic profiles of Titan's surface.

Relative surface elevations are recorded along nadir tracks using Cassini and Titan ephemerides knowledge along with the obtained range from spacecraft to surface. On high resolution altimetry mode (between 4,000 km and 9,000 km of altitude), Cassini uses its nadir-pointing 4 meters antenna to transmit and receive bursts of 15 chirp pulse signals every 3.333 seconds at a system bandwidth of $4.25 \mathrm{MHz}$ [3]. The resulting altimetry measurements have a height resolution of about 35 meters. The absolute ephemeris error and the uncertainty in pointing knowledge are the major sources of error for the derived elevations. However, when the pointing is well controlled both estimates are accurate at a sub-100m level [25]. A classical processing of Cassini burst, after range compression and incoherent average of burst's pulses, allows obtaining a horizontal resolution ranging between 50 and $6 \mathrm{~km}$, depending on the spacecraft altitude.

Among the various regions observed by Cassini on both altimetry and SAR mode, we selected a study area in the Fensal dune field, where the altimetry path went across during the T30 flyby (May 2007). Only fully covered by dunes 3-dB beam altimetry footprints have been considered. In SAR images a number of dune-interdune cycles ranging from 8 to 12 in each selected altimetry footprint can be distinguished.

Footprint selection performed over this dune field includes every footprint between the $750^{\text {th }}$ and the $1160^{\text {th }}$ burst acquisition. In this case horizontal resolution ranges from 26 to $31 \mathrm{~km}$.

Assuming a Gaussian heights distribution for the dune fields, we estimated the dunes heights from altimetry data via a Maximum Likelihood Estimation (MLE) procedure applied along with a non-coherent Cassini electromagnetic signal model $[18,20]$. Because of the very high percentages of superimposition area between subsequent footprints we applied this procedure after an incoherent average of 15 altimetry echoes obtaining 20 significative dunes heights $($ Sdh $=$ $4 \cdot \mathrm{rms}$ height) estimations in order of 55 - 110 meters (see Fig.1), these values match with previously estimated values given by radarclinometry $[12,14]$ and SAR - stereo [13]. 


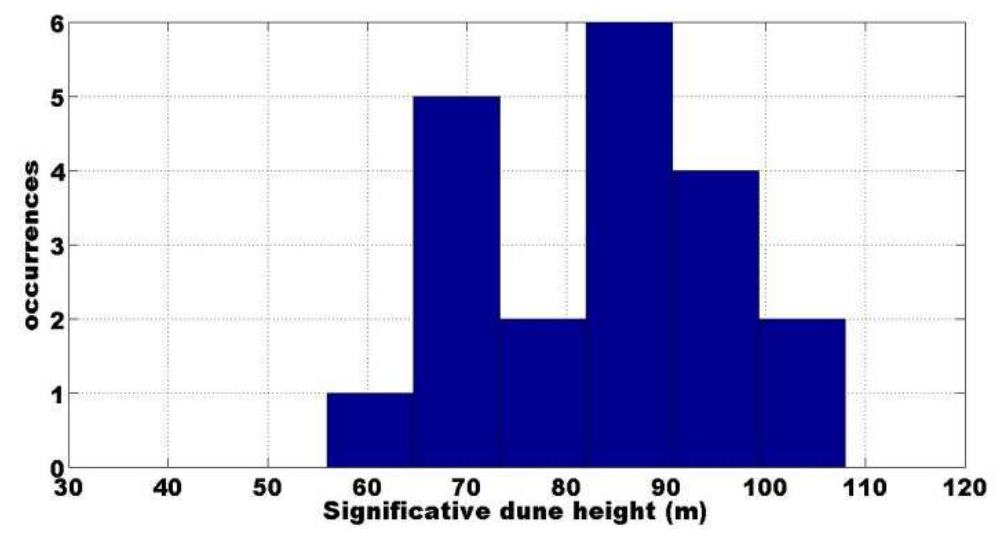

Figure 1. Significative dune height ( $\mathrm{Sdh}=4 \cdot \mathrm{rms}$ height) distribution on the Fensal dune field.

\section{DUNES ANALYSIS THROUGH SAR IMAGES IN FENSAL REGION}

Some areas covered by the SAR images acquired in Fensal region are characterized by bright and dark stripes that correspond to longitudinal dunes (Fig. 2b).

The mean interdune spacing in a localized area can be estimated through the analysis of the corresponding portion of the SAR image in the Fourier domain. From the Fourier transform image, it is possible to find the dominant spatial frequency and thus compute the wavelength of the periodic surface power spectrum, corresponding to the interdune spacing. In particular, for each area of interest, these steps have been applied:

1. Median filter to reduce very high frequencies (i.e. speckle);

2. Fourier transform the image;

3. Gaussian-shape filter in order to remove the very low frequencies;

4. Find the dominant frequency in the azimuth $\left(\mathrm{f}_{\mathrm{a}}\right)$ and range $\left(\mathrm{f}_{\mathrm{r}}\right)$ directions;

5. Compute the wavelength (i.e. the interdune spacing): $\lambda=\frac{1}{\sqrt{f_{a}{ }^{2}+f_{r}{ }^{2}}}$.

This procedure has been applied to each portion of the SAR image corresponding to areas where dune height estimation has been performed from altimetry data (fig. 4) [26].

By taking into account all the available flybys (T3, T17, T28, T25 and T29) and dividing the dark from the bright areas it was possible to identify an expected decreasing trend between backscattering and sensor nominal incidence angle for both areas (Fig.2c).

In general, the variability around a mean trend value that is present in both the dark and bright areas can be caused by several factors, such as the different slopes and heights of dunes, the amount of sand supply, the sand composition and the surface roughness.

The different values between backscattering of dark and bright areas (i.e. blue and red points respectively in Fig.2c) can be generally explained by considering more than one single factor. For instance, assuming the same material properties and root mean square (rms) height $\sigma_{h}$ over the two areas, backscattering difference values could be caused by a variation of the local incidence angle which depends on the varying topography of the dunes. In this case the part of the dune oriented to the radar should result the brightest one. 


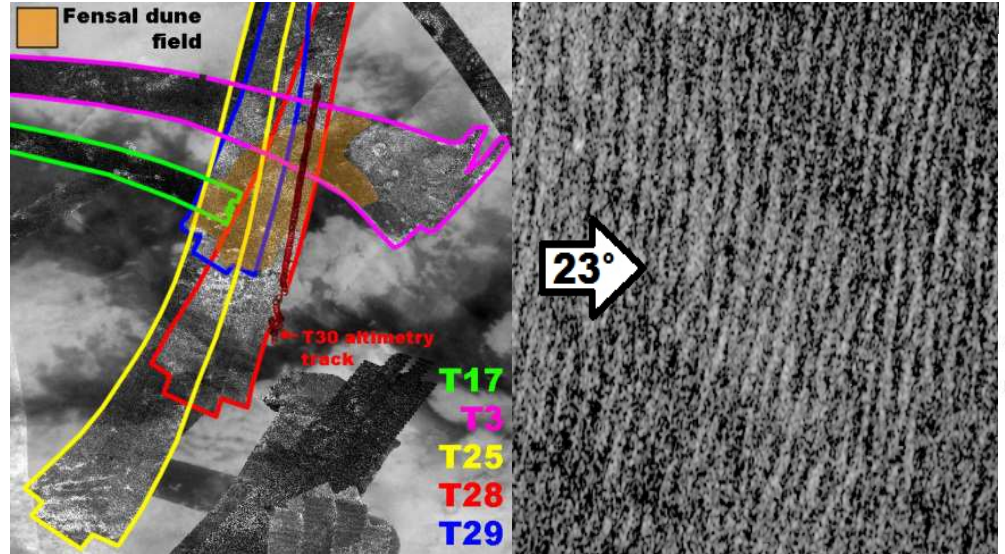

(a) (b)

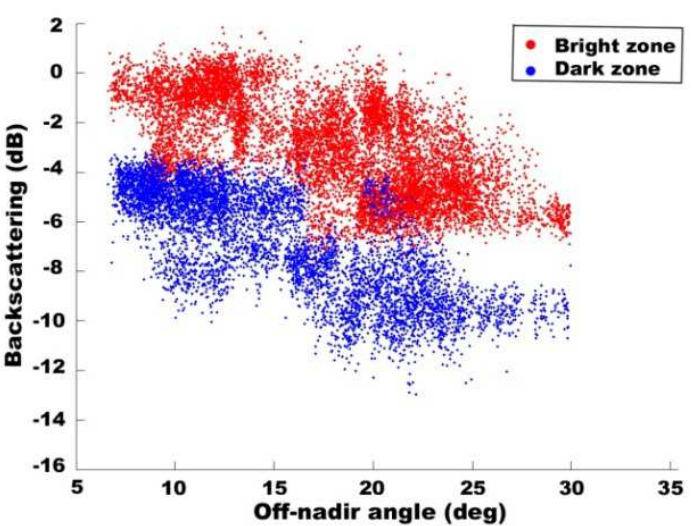

(c)

Figure 2: (a) map combining all the RADAR swaths on Fensal dune fields shows the parallel axis SAR observations to dunes (T3, T17) as well as the perpendicular (T25, T28, T29); (b) close view of the same area from the T3 SAR flyby; (c) backscattering coefficients versus off-nadir angle; blue and red points refer to samples lying in dark and bright stripes respectively, as extracted from T3, T17, T25 and T28 SAR swaths.

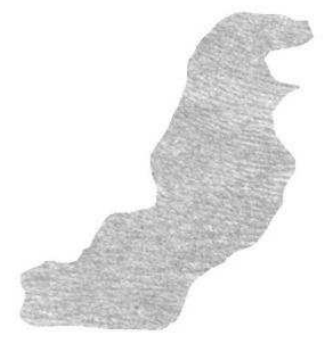

(a)

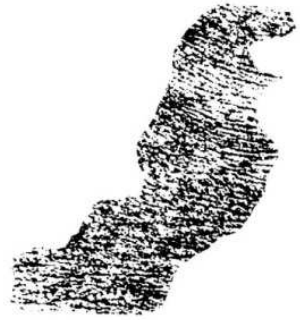

(b)

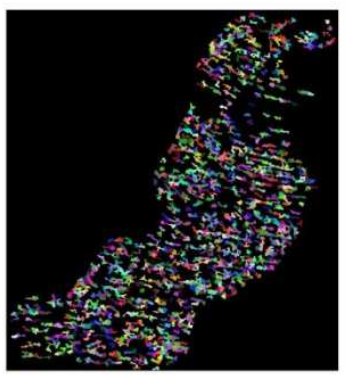

(c)

Figure 3. Dune field areas extracted from the SAR image acquired during the T28 flyby. Original image (a), classification between dark and bright stripes (b), ROIs selected for the dark area (c).

\section{CHARACTERIZATION OF SUPERIMPOSED ROUGHNESS ON DUNES}

To estimate a possible range of values for the surface roughness of dunes, some hypothesis are needed:

- Only surface scattering generated at the air-sand interface is relevant. Volume scattering is assumed negligible;

- Dune field is approximated by a sinusoid;

- Backscattering variability detected in the SAR image pixels is caused by different incidence angle at the surface and not by difference in the surface material.

We retrieved dunes slope by combining SAR and altimeter data. We have analyzed a perpendicular axis of the SAR observations with respect to dune directions from T28 in the Fourier domain and we found the dominant spatial frequency (Fig.4). 


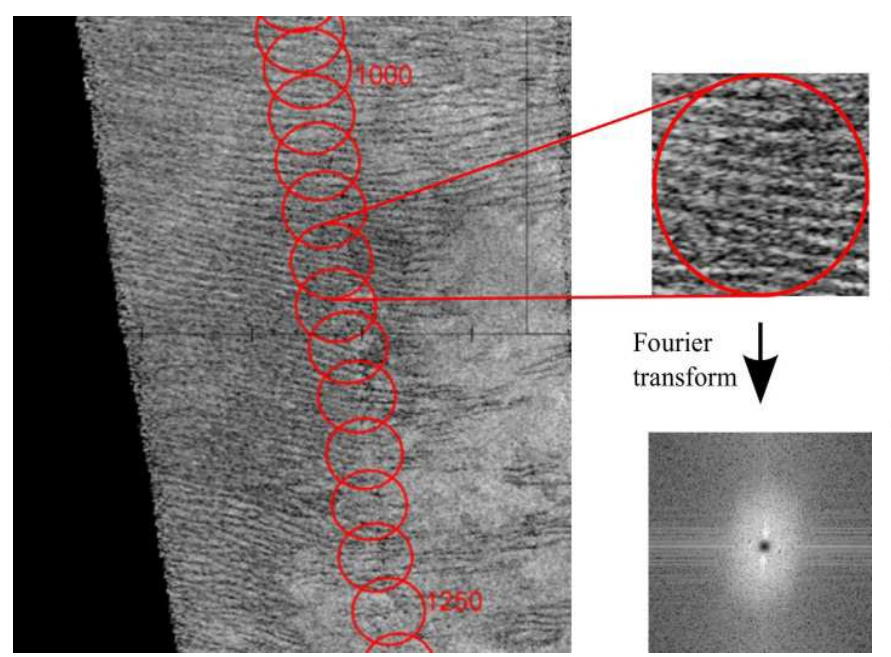

(a)

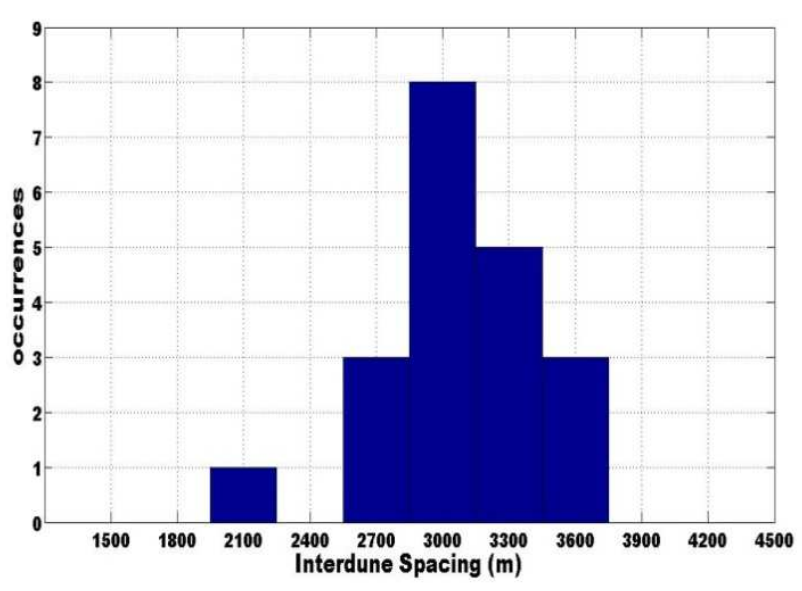

(b)

Figure 4. (a) Through an analysis in the Fourier domain of SAR images on dunes it is possible to find their dominant spatial frequency; (b) estimated interdune spacing.

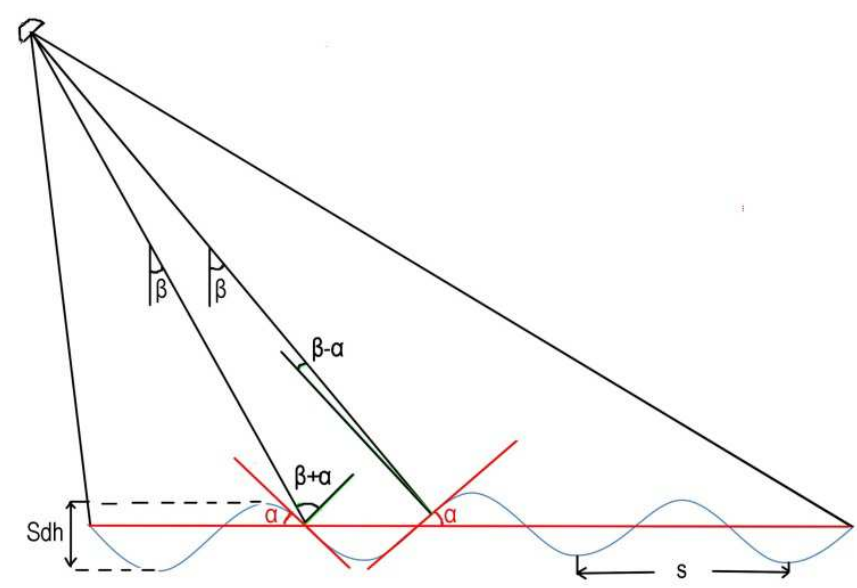

(a)

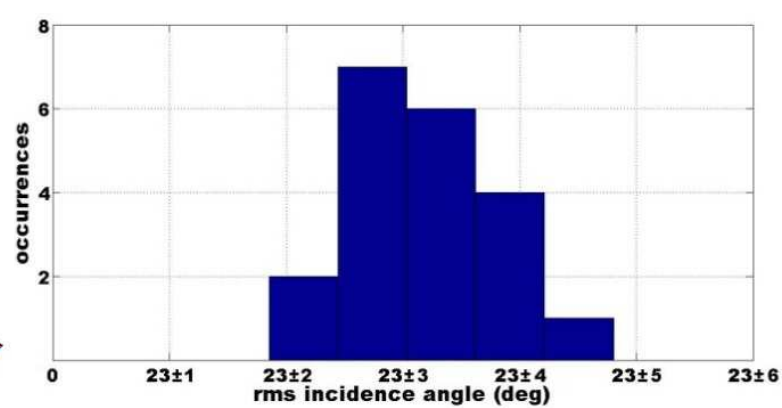

(b)

Figure 5. System geometry (a); rms incidence angle along T30 altimetry track on Fensal dune field (SAR off-nadir angle $\beta$ is $\left.23^{\circ}\right)(\mathrm{b})$.

This information was used, as described in Section 4, to compute the wavelength of the periodic surface power spectrum, corresponding to the white zones spacing on SAR image. Considering the image scale equal to $175 \mathrm{~m}$ per pixel, we derived the dunes rms incidence angle along Fensal region by means of Significative dune height $\left(\operatorname{Sdh}=4 \cdot \sigma_{h}\right)$ estimated from T30 altimetry data (Fig.1) and mean dune spacing $\bar{S}$ from T28 SAR image (Fig.4). The derived angles range about $2^{\circ}-4^{\circ}$ (see Fig.5b) and are given by the simple formula:

$$
\alpha=\tan ^{-1}[S d h /(\bar{s} / 2)]
$$




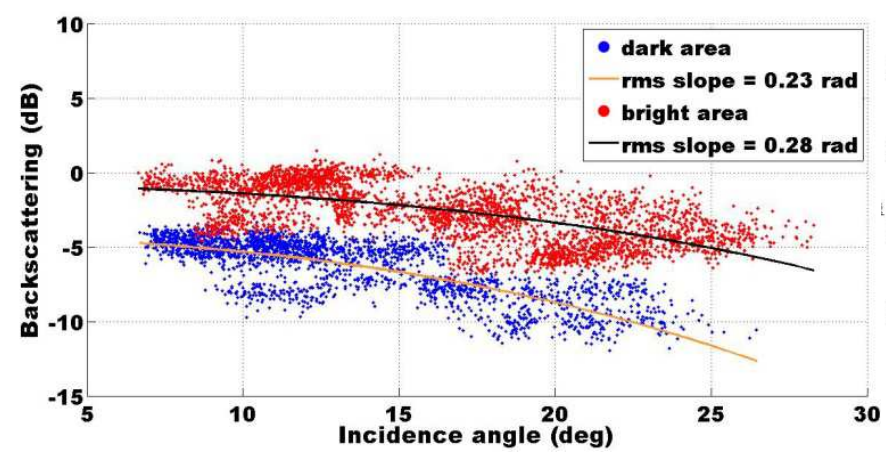

(a)

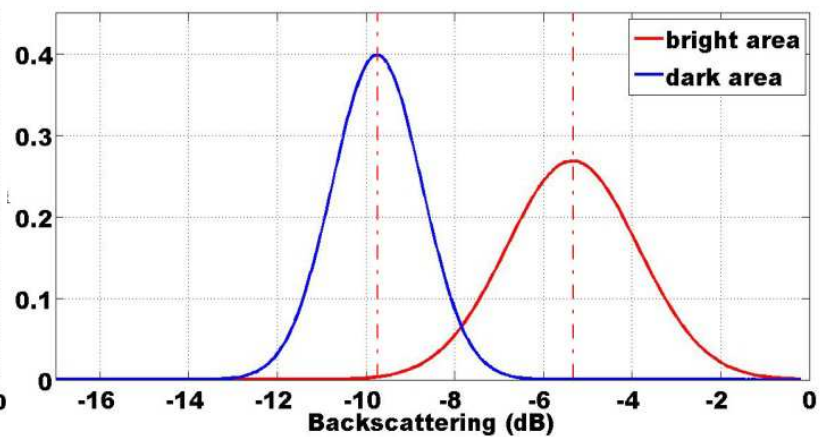

(b)

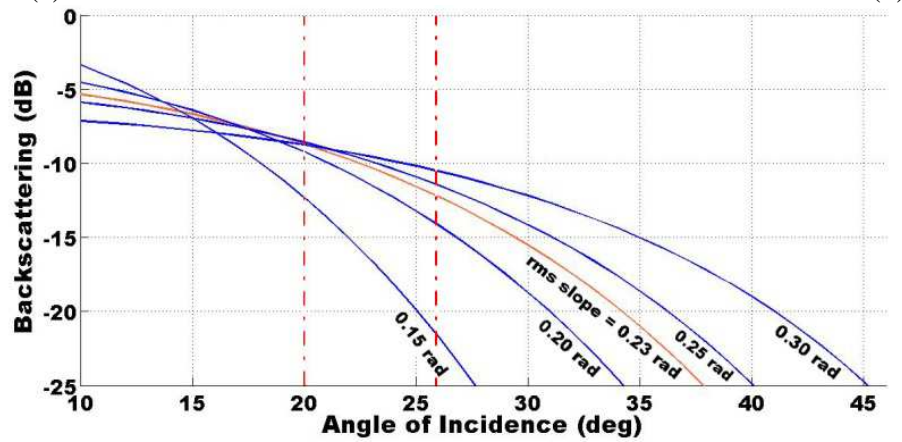

(c)

Figure 6: (a) Backscattering coefficients versus nominal incidence angle and GO model best fitting. Blue and red points refer to samples lying in dark and bright stripes respectively, as extracted from T25, T28 and T29 SAR swaths; (b) Distribution of values using T3 and T17 SAR swath (mean values difference is equal to $4.4 \mathrm{~dB}$ ); (c) Geometric Optics model curves for different rms slopes on dark area. Dotted lines indicate the extreme incidence angles $\left(20^{\circ}-26^{\circ}\right)$ due to off-nadir and dune slopes observed from T3 SAR image.

Electromagnetic models have been adopted in the past to retrieve information about the roughness of natural surfaces [16].

The Integral Equation Model (IEM) is a model with a wide range of variability which can be used for both surfaces with small and large values of roughness.

Due to the high frequency of Cassini radar $(13.78 \mathrm{GHz})$, we can assume the standard deviation of heights within the SAR resolution (about $300 \mathrm{~m} \times 300 \mathrm{~m}$ ) larger respect to the wavelength $(2.17 \mathrm{~cm})$. In this high frequency region the IEM reduces naturally to the Geometric Optics (GO) solution [21]. We can assume valid the Kirchhoff approximation as well [28]. Thus the backscattering coefficient is given by:

$$
\sigma(\theta)=\frac{|R(0)|^{2} e^{-\left(\frac{\tan ^{2} \theta}{2 \sigma^{2}\left|\rho^{\prime \prime}(0)\right|}\right)}}{2 \sigma^{2}\left|\rho^{\prime \prime}(0)\right| \cos ^{4} \theta}
$$

where $\theta$ is the incidence angle, $\sigma$ is the rms slope, $|R(0)|$ is the Fresnel reflection coefficient evaluated at normal incidence, $\rho$ is the correlation coefficient and $\left|\rho^{\prime \prime}(0)\right|$ is the second derivative of $\rho$ evaluated in the origin of the function [16].

The last step is the extraction of backscattering values from dark and bright areas on T25, T28 and T29 SAR (perpendicular axis SAR observations to Fensal dunes). Zones reported in Fig.6a have been obtained from SAR pixels acquired at different off-nadir angles over the two areas (dark and bright). By investigating the angular backscattering behavior over Fensal, we found a best fit with the GO model for values of rms slopes of around 0.23 and 0.28 rad for the dark and the bright area respectively (Fig.6a).

However, these possible values of roughness do not explain the total difference in the backscattering coefficient values between bright and dark areas. GO model shows that at the incidence angle of $23^{\circ} \pm 3^{\circ}$ the variation of backscattering should be in order of $2.1 \mathrm{~dB}$ (Fig. 6c; for rms slope of $0.23 \mathrm{rad}$ ). As indicated in Fig.6b, the total backscattering 
difference detected is around $4.4 \mathrm{~dB}$. Differently from Fig.6a, the dataset we used Fig.6b includes T3 and T17 SAR swaths. This choice is based on the consideration that the parallel axis SAR observations to dunes are the only swaths that should include the backscattering dependence from dune slope.

One possible interpretation is that the total variation of backscattering coefficients could be caused by an incorrect modeling of the dune shape combined with a roughness and dielectric properties variability as well.

Concerning dune's shape modeling, because of the nonlinear interaction at the interface between the surface and the atmosphere, the wave crests could be more peaked than the wave troughs. This effect should be eventually taken into account by giving to the surface height probability density function a non-symmetric behavior that is a non- zero skewness coefficient [27, 29].

Further investigation is therefore needed to evaluate and eventually separate the different contributions given by these factors.

\section{CONCLUSION}

SAR images together with altimetry data have been analyzed to investigate the topographic and morphologic properties of Fensal dunes on Titan.

Both datasets have been used to estimate dunes slope and to derive incidence angles values. GO backscattering model applied to a multi-angular backscattering observations dataset allowed inferring about possible values for small scale roughness that should characterize dune field surfaces.

We found that dunes slopes within superimposed roughness evaluated by mean of GO model simulations does not completely justify the backscattering difference between bright and dark areas on dunes.

Further investigation is needed to evaluate and eventually separate the contribution given by an incorrect modeling of the dune shape as well as a roughness and dielectric properties variability in the dune areas.

\section{ACKNOWLEDGMENT}

The authors would like to thank Italian Space Agency (ASI) for funding the research activities in the framework of the "Cassini Huygens, fase E2 attività scientifica" under contract n. I/015/09/0.

\section{REFERENCES}

[1] Elachi, C., Allison, M.D., Borgarelli, L., Encrenaz, P., Im, E., Janssen, M.A., Johnson, W.T.K., Kirk, R.L., Lorenz, R.D., Lunine, J.I. and others, "RADAR: The Cassini Titan Radar Mapper," Space Sci. Rev. 115(1), 71-110 (2004).

[2] Le Gall, A., Janssen, M.A., Wye, L.C., Hayes, A.G., Radebaugh, J., Savage, C., Zebker, H., Lorenz, R.D., Lunine, J.I., Kirk, R.L., Lopes, R.M.C., Wall, S., Callahan, P., Stofan, E.R., and Farr, T., "Cassini SAR, radiometry, scatterometry and altimetry observations of Titan's dune fields", Icarus 213(2), 608-624 (2011).

[3] Radebaugh, J., Lorenz, R., Farr, T., Paillou, P., Savage, C. and Spencer, C., "Linear dunes on Titan and earth: Initial remote sensing comparisons," Geomorphology 121(1-2), 122-132 (2010).

[4] Lunine, J.I., "The hydrologic cycle on Saturn's moon, Titan," Memorie della Società Astronomica Italiana Supplementi 19, 75 (2012).

[5] Le Gall, A., Hayes, A.G., Ewing, R., Janssen, M.A., Radebaugh, J., Savage, C. and Encrenaz, P., "Latitudinal and altitudinal controls of Titan's dune field morphometry," Icarus 217(1), 231-242 (2012).

[6] Le Gall, A., Janssen, M.A., Wye, L.C., Radebaugh, J., Lorenz, R.D. and Team, C.R., "Regional variations among Titan's dunes: Belet versus Fensal dune fields," European Planetary Science Congress 2010 5, 247 (2010).

[7] Le Hégarat-Mascle, S., Zribi, M. and Ribous, L., "Retrieval of elevation by radarclinometry in arid or semi-arid regions," International Journal of Remote Sensing 26(13), 2877-2899 (2005).

[8] Neish, C.D., Lorenz, R.D., Kirk, R.L. and Wye, L.C., "Radarclinometry of the sand seas of Africa's Namibia and Saturn's moon Titan," Icarus 208(1), 385-394 (2010).

[9] Rodriguez, S., Paillou, P., Dobrijevic, M., Ruffié, G., Coll, P., Bernard, J.M. and Encrenaz, P., "Impact of aerosols present in Titan's atmosphere on the CASSINI radar experiment," Icarus 164(1), 213-227 (2003). 
[10] Paillou, P., Bernard, D., "Modeling the SAR Backscatter of Linear Dunes on Titan,"EPSC-DPS2011 6,149 (2011).

[11] Le Mouélic, S., et al., "Mapping and interpretation of Sinlap crater on Titan using Cassini VIMS and RADAR data," J. Geophys. Res. 113, (2008).

[12] Neish, C.D., Lorenz, R.L. Kirk, and L.C. Wye, "Radarclinometry of the sand seas of Africa's Namibia and Saturn's moon Titan”, Icarus 208, 385-394, 2010.

[13] Kirk, R L., et al., "A three dimensional view of Titan's surface features from cassini RADAR stereogrammetry”, 40th Lunar and Planetary Science Conference, Abstract \# 1413 (The Leagues, TX, USA), 2009.

[14] R.D. Lorenz, S. Wall, G. Picardi, R. Seu et al., "The Sand Seas of Titan: Cassini RADAR Observations of Longitudinal Dunes", Science, 312, pp. 724-727, 2006.

[15] Mastrogiuseppe M., Poggiali V., Seu. R., Picardi G., “Advanced processing of altimetry Cassini radar data”, Proc. of the 3rd Microwaves, Radar and Remote Sensing Symposium (MRRS-2011), Kiev, Ukraine, Aug. 25-27, 2011.

[16] Ulaby, Moore, Fung, "Microwave remote sensing, vol. I", Artec House.

[17] Seber G. A. F., "Multivariate Observations”, Hoboken, NJ: John Wiley \& Sons, Inc., 1984.

[18] Montefredini E., Morelli F., Picardi G., Seu R., “A non-coherent surface backscattering model for radar observation of planetary bodies and its application to Cassini radar altimeter”, Planet.Space Sci., Vol.43, No.12, pp.1567-1577, 1995.

[19] MacQueen, J. B., "Some Methods for classification and Analysis of Multivariate Observations", Proceedings of 5th Berkeley Symposium on Mathematical Statistics and Probability, Berkeley, University of California Press, 1:281-297 (1967).

[20] Alberti, G, Festa, L., Papa, C., Vingione, G., “A waveform model for near-nadir radar altimetry applied to Cassini mission to Titan", 2009.

[21] Fung, A. K., Li Z., Chen, K.S., "Backscattering from a Randomly Rough Dielectric Surface", ieee transactions on geoscience and remote sensing, vol. 30, no. 2, march 1992.

[22] Elachi, C., Wall, S., Janssen, M., Stofan, E., Lopes, R., Kirk, R., Lorenz, R., Lunine, J., Paganelli, F., Soderblom, L., Wood, C., Wye, L., Zebker, H., Anderson, Y., Ostro, S., Allison, M., Boehmer, R., Callahan, P., Encrenaz, P., Flamini, E., Franceschetti, G., Gim, Y., Hamilton, G., Hensley, S., Johnson, W., Kelleher, K., Muhleman, D., Picardi, G., Posa, F., Roth, L., Seu, R., Schaffer, S., Stiles, B., Vetrella, S., and West R.: “Titan Radar Mapper observations from Cassini's Ta and T3 fly-bys", Nature, 441, 709-713, doi:10.1038/nature0486 (2006).

[23] Wood, C. A., R. Lorenz, R. Kirk, R. Lopes, K. Mitchell, and E. Stofan, "Impact craters on Titan”, Icarus, 206, 334344, doi:10.1016/j.icarus.2009.08.021, 2010

[24] Lopes, R. M. C., Stofan, E. R., Peckyno, R., Radebaugh, J., Mitchell, K. L., Mitri, G., Wood, C. A., Kirk, R. L., Wall, S. D., Lunine, J. I., Hayes, A., Lorenz, R., Farr, T., Wye, L., Craig, J., Ollerenshaw, R. J., Janssen, M., Le Gall, A., Paganelli, F., West, R., Stiles, B., Callahan, P., Anderson, Y., Valora, P., Soderblom, L. and the Cassini RADAR Science Team, "Distribution and interplay of geologic processes on Titan from Cassini RADAR data", Icarus, 205, 540-558, doi:10.1016/j.icarus.2009.08.010, 2010.

[25] Zebker, H. A., Y. Gim, P. Callahan, S. Hensley, R. Lorenz, and the Cassini RADAR Science Team, "Analysis and interpretation of Cassini Titan radar altimeter echoes", Icarus, Volume 200, Issue 1, Pages 240-255, March 2009.

[26] Qong, M., "Sand dune attributes estimated from SAR images," Remote sensing of environment 2, 217-228, 2000.

[27] Picardi G., Masdea A., Melacci P. T., Seu R., "Surface estimation in bistatic radar altimetre", Radar Conference, 2008 RADAR '08. IEEE, 26-30 May 2008.

[28] Fung A.K., Eom H.J., “Coherent Scattering of a Spherical Wave from an Irregular Surface”, IEEE Tr. Antennas Propagat. Vol. AP-31, pp. 68-72, Jan. 1983.

[29] Lancaster, N., “Geomorphology of Desert Dunes”, Routeledge, London (1995). 